in vivo $35: 731-741(2021)$

doi:10.21873/invivo.12314

\title{
Double-layered Nanofibrous Patch for Prevention of Anastomotic Leakage and Peritoneal Adhesions, Experimental Study
}

\author{
JACHYM ROSENDORF ${ }^{1,2}$, MARKETA KLICOVA ${ }^{3}$, LENKA CERVENKOVA ${ }^{2,4}$, \\ RICHARD PALEK ${ }^{1,2}$, JANA HORAKOVA ${ }^{3}$, ANDREA KLAPSTOVA ${ }^{3}$, PETR HOSEK ${ }^{2}$, \\ VLADIMIRA MOULISOVA ${ }^{2}$, LUKAS BEDNAR ${ }^{2}$, VACLAV TEGL ${ }^{2,5}$, ONDREJ BRZON $^{2}$, \\ ZBYNEK TONAR ${ }^{2,6}$, VLADISLAV TRESKA ${ }^{1}$, DAVID LUKAS $^{3,7}$ and VACLAV LISKA ${ }^{1,2}$ \\ ${ }^{1}$ Department of Surgery, Faculty of Medicine in Pilsen, Charles University, Prague, Czech Republic; \\ ${ }^{2}$ Biomedical Center, Faculty of Medicine in Pilsen, Charles University, Prague, Czech Republic; \\ ${ }^{3}$ Department of Nonwovens and Nanofibrous Materials, Faculty of Textile Engineering, \\ Technical University of Liberec, Liberec, Czech Republic; \\ ${ }^{4}$ Department of Pathology, Third Faculty of Medicine, Charles University, Prague, Czech Republic; \\ ${ }^{5}$ Department of Anesthesiology and Intensive Care Medicine, Faculty of Medicine in Plzen, Pilsen, Czech Republic; \\ ${ }^{6}$ Department of Histology and Embryology, Faculty of Medicine in Pilsen, \\ Charles University, Prague, Czech Republic; \\ ${ }^{7}$ Department of Chemistry, Faculty of Science, Humanities and Education, \\ Technical University of Liberec, Liberec, Czech Republic
}

\begin{abstract}
Background/Aim: Anastomotic leakage is a feared complication in colorectal surgery. Postoperative peritoneal adhesions can also cause life-threatening conditions. Nanofibrous materials showed their pro-healing properties in various studies. The aim of the study was to evaluate the impact of double-layered nanofibrous materials on anastomotic healing and peritoneal adhesions formation. Materials and Methods: Two versions of double-layered materials from polycaprolactone and polyvinyl alcohol were applied on defective anastomosis on the small intestine of healthy pigs. The control group remained with uncovered defect. Tissue specimens were subjected to histological analysis and adhesion scoring after 3 weeks of observation. Results: The wound healing was inferior in the experimental groups, however, no anastomotic leakage was observed and the applied material always kept covering the defect. The extent of adhesions was larger in the experimental groups.
\end{abstract}

This article is freely accessible online.

Correspondence to: Jachym Rosendorf, MD, Biomedical Center, Alej Svobody 80, Plzen, 32 600, Czech Republic. Tel: +420 377103642, e-mail: jachymrosendorf@gmail.com

Key Words: Anastomotic leak, colorectal surgery, anastomotic reinforcement, nanofibrous materials, polycaprolactone.
Conclusion: Nanofibrous materials may prevent anastomotic leakage but delay healing.

Anastomotic leakage (AL) is a result of partial or total dehiscence of an anastomosis on the gastrointestinal (GI) tract. It is a feared complication especially in colorectal surgery that usually appears in the early postoperative period (1-4). The reported rates of AL in colorectal surgery in general are between 6 and 7\% (5-7). In rectal cancer surgery in particular, the rate reaches up to $11 \%$ or even higher according to some studies (8-10). The numbers differ as the definitions of leakage are variable (11).

There are three clinical grades of AL following anterior resection of the rectum according to the system proposed by the International Study Group of Rectal Cancer $(12,13)$. Grade A presents with no symptoms, no laboratory deviations and is detectable only by radiologic evaluation as a contained leak. No intervention is needed. Grade B manifests with discomfort of the patient, possible purulent drain secretion and laboratory changes. Grade B ALs can be approached by application of antibiotics or drainage in some cases; reoperation is not required. A grade $\mathrm{C} \mathrm{AL}$ results in peritonitis. It is a life-threatening condition and requires reoperation. Grade B and especially grade C ALs are associated with generally higher morbidity and mortality, worse clinical outcome, prolonged stay in hospital, higher risk of stoma and higher treatment costs (14). Higher local 
malignancy recurrence has been observed in several studies after AL alongside shorter overall survival of the patients suffering from AL (15-17). AL is therefore to be considered as an enormous socio-economic burden in colorectal surgery.

Only little is known about anastomotic healing and the processes involved in anastomotic failure. A thorough description of the results of the healing process should therefore be implemented in any experimental work focusing on the anastomotic healing. A standard histological evaluation comprises (i) intestinal wall morphology assessment by comprehensive staining, (ii) re-epithelization assessment, and (iii) stereological evaluation of volume fractions of collagen, endothelial cells and inflammatory cells (18). To the best of our knowledge, there are currently no complex histological scoring systems for evaluation of the integrity of intestinal wall focusing on each intestinal wall layer separately.

Many studies have been conducted to identify the risk factors associated with the occurrence of AL in colorectal surgery. Patient-specific factors, perioperative care, surgical treatment and technique were analyzed. It is clear from these studies that the occurrence of AL is determined by many factors. Some studies list the experience of the performing surgeon among these factors. This observation may suggest that a technical fault can be involved in the development of AL (19-21).

Another adverse effect of intra-abdominal surgical procedures is the formation of peritoneal adhesions (PAs). PAs can develop in various amounts and in different forms ranging from thin fragile connections to thick vascular bonds $(22,23)$. PAs can often cause abdominal discomfort or even more serious complications including ileus. Besides that, subsequent surgical procedures are more technically challenging due to PAs. No routine use of currently sold antiadhesives is recommended because of lack of clinical data (23). One of the conditions for the formation of peritoneal adhesions is the contact of the two peritoneal surfaces. Hydrophobicity is suspected to belong among the factors determining the pro- or anti-adhesive properties of surgical materials.

Over the recent decades, various materials have been tested both for reinforcement of intestinal anastomoses and for prevention of the formation of peritoneal postoperative adhesions. Experimental studies on new supporting materials and techniques in general often show positive results of reinforcing materials in animal models according to a systematic review conducted by Yauw et al. (24). The quality of such studies is however highly variable, as are also their experimental settings including species, location of anastomosis, perioperative treatment and, most importantly, methodology of the assessment of the healing quality (24). Furthermore, none of the reinforcing materials is currently recommended for use in colorectal surgery (25).

Nanofibrous and microfibrous materials are nonwoven fabrics created from various polymer solutions. They have been proved to have a positive influence in experimental studies of wound healing (26). However, their impact on anastomotic healing, formation of peritoneal adhesions and on the risk of AL has not been studied thoroughly yet. To the best of our knowledge, the only study focusing on nanofibrous patches has been performed by our research group (27). In this study, the material consisting of polycaprolactone appeared safe and easy to use with no negative clinical and histological effects in an experimental porcine model of anastomosis on the small intestine. However, in the experimental settings with no complications, the possible positive effect of the material on the risk of AL development was not distinguishable. To address this shortcoming, the experimental design was modified for the current study by including a standardized defect in all of the performed anastomoses. A new nanofibrous patch from polyvinyl alcohol (PVA) and polycaprolactone (PCL) was developed by our team and tested in vitro for its physical properties and biocompatibility (28).

The aims of this study were: 1) To assess the impact of the developed composite microfibrous materials on anastomotic healing in an experimental model of a technically defective intestinal anastomosis in pig. 2) To develop and use a new semiquantitative system for the evaluation of intestinal integrity in the site of anastomosis for more complex anastomotic healing assessment.

\section{Materials and Methods}

Development of materials. Double-layered PCL/PVA nanofibrous mats were prepared in two variants differing in the degree of hydrolysis of the PVA component. The solution of PVA with high degree of hydrolysis (PVA1) was prepared by diluting the commercially available solution of $16 \% \mathrm{PVA}^{\mathrm{Mowiol}}{ }^{\circledR}\left(\mathrm{M}_{\mathrm{w}}\right.$ $125.000 \mathrm{~g} / \mathrm{mol}, 98.0-98.8 \%$ hydrolysis, Sigma Aldrich, St. Louis, MO, USA) in ethanol (Penta Chemicals, Prague, Czech Republic) and deionized water (1:4 volume fractions) in a final concentration of $10 \% \mathrm{w} / \mathrm{w}$. PVA Mowiol ${ }^{\circledR}\left(\mathrm{M}_{\mathrm{w}} 130.000 \mathrm{~g} / \mathrm{mol}, 88 \%\right.$ hydrolysis, Merck, Darmstadt, Germany) was used to prepare aqueous solution of the PVA with low degree of hydrolysis (PVA2) in a final concentration of $12 \% \mathrm{w} / \mathrm{w}$. Polymeric granulate of PCL $\left(\mathrm{M}_{\mathrm{w}} 43.000\right.$ $\mathrm{g} / \mathrm{mol}$, Polysciences, Hirschberg an der Bergstrasse, Germany) was dissolved in chloroform, acetic acid and ethanol solution (8:1:1 volume fractions) in a concentration of $16 \% \mathrm{w} / \mathrm{w}$.

The double-layered nanofibrous mats were prepared using the needleless electrospinning device Nanospider ${ }^{\mathrm{TM}}$ 1WS500U (Elmarco, Liberec, Czech Republic) by the method of sequential electrospinning. Firstly, the hydrophilic layer of PVA1 or PVA2 was created. The PCL fibres were then deposited directly on the previously electrospun PVA1/PVA2 layer. Scanning electron microscopy (PHENOMTM, Fei Company, Hillsboro, OR, USA) was employed to evaluate the structure of the materials. We followed the same protocols as in our recent publication (28).

Experimental design. We randomly allocated 24 healthy male and female Prestice black-pied pigs into 3 groups, 8 animals each. A 
defective anastomosis on the small intestine was constructed in all animals. Animals in experimental groups PCL/PVA1 and PCL/PVA2 received one of the two types of reinforcing material (respecting the group) and the animals in the Control group remained with uncovered anastomotic defect. The animals were observed for 21 days. Sample collection, macroscopic and histologic assessments followed.

Surgery. The animals were weighed prior to the surgery. Anesthesia was induced by intramuscular application of $10 \mathrm{mg} / \mathrm{kg}$ of ketamine (Narkamon, Spofa, Prague, Czech Republic), $5 \mathrm{mg} / \mathrm{kg}$ of azaperone (Stresnil, Jannssen Phramaceutica, Beerse, Belgium) and $0.5 \mathrm{mg}$ atropine (Atropin Biotika, Hoechst Biotika, Martin, Slovak Republic). Laryngeal tube was then inserted while maintaining general anaesthesia using intravenous propofol administration (1\% mixture $5-10 \mathrm{mg} / \mathrm{kg} / \mathrm{h}$ Propofol, Fresenius Kabi, Oslo, Norway) in combination with Fentanyl 1-2 $\mu \mathrm{g} / \mathrm{kg} / \mathrm{h}$ (Fentanyl Torrex, Chiesi cz, Prague, Czech Republic) for analgesia. $1.2 \mathrm{~g}$ of Augmentin (GlaxoSmithKline Slovakia, Bratislava, Slovak Republic) was used for antibiotic prophylaxis; half of the dose was administered prior to surgery and the other half two $h$ after its beginning.

A ProPort Plastic Venous Access System with PolyFlow polyurethane catheter (Deltec, Smiths Medical, Minneapolis, MN, USA) was implanted and introduced through one of the jugular veins as the first surgical procedure. The abdominal cavity was then approached via an upper middle laparotomy. The small intestine was transected $70 \mathrm{~cm}$ from the duodenojejunal junction. All swabs used during the surgery were wet in order to prevent extensive formation of peritoneal adhesions. A hand-sutured end-to-end anastomosis was constructed with MONOSYN 4/0 (Glycolide 72\%, Caprolactone $14 \%$, Trimethylencarbonate $14 \%$ ) monophilament suture line (BBraun, Germany) using seromuscular extramucosal running suture. An artificial defect on the antimesenteric side of the anastomosis with a standard diameter of $0.75 \mathrm{~cm}$ was created using a draining tube (Figure 1). The initial knot was always placed on the mesenteric side while the closing knot was placed about one quarter of the intestinal circumference from it. The position of the defect was marked with a single non-absorbable stitch placed orally to the anastomosis. A sheet of PCL/PVA1 or PCL/PVA2 material was placed onto the anastomosis and positioned to adhere to the intestinal wall and to cover the whole anastomosis with the defect (the hydrophilic PVA side facing the intestine). The viscera were placed back to the abdominal cavity and the abdominal wall was reconstructed. All surgical procedures were performed by the same surgeon.

The animals were observed for three weeks following the surgery and fed according to pre-defined re-alimentation scheme. Their ability to feed according to the schedule was recorded alongside any clinical changes, signs of GI obstruction, abdominal diameter enlargement, stool frequency, vomiting, and body temperature elevation.

Follow-up. Blood samples were taken during the experiment at five time points: on day 0 before the application of the material, exactly two $h$ after the application of the nanomaterial, on the 7th postoperative day (POD), on the 14th POD, on the 21st POD. Basic biochemical parameters were tracked in these samples (bilirubin, GGT, ALT, AST, ALP, albumin, urea, and creatinine) to observe deviations in the animals' metabolism. The weight of the animals was also measured in defined time points: preoperatively at the beginning of the experiment, on the $3^{\text {rd }}, 7^{\text {th }}, 14^{\text {th }}, 21^{\text {st }}$ POD.

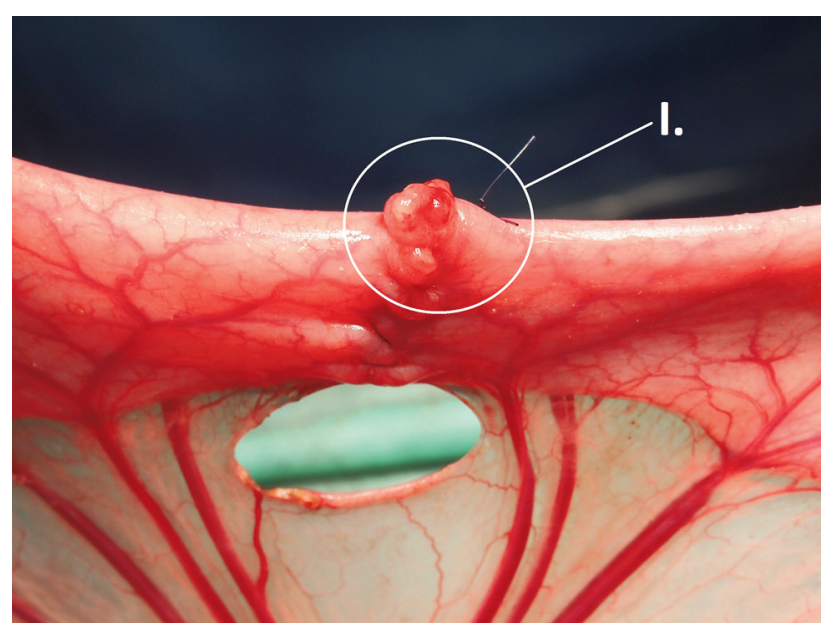

Figure 1. Construction of anastomosis. An intestinal anastomosis with defect on the antimesenteric side (I.), the size of the defect is standardized using a drain tube.

After the observation period, the following exploration and sample collection surgery was performed under general anaesthesia. The abdominal cavity was searched for signs of any complications, intestinal matter, the GI tract checked for signs of obstruction (intestinal wall thickening, intestinal diameter enlargement, intestinal adhesions causing convolutes and sharp bents of the intestine, strictures of the intestine in any location and strictures of the anastomosis itself). Organs involved in adhesions in the rest of the abdominal cavity were also noted. Afterwards, the specimen of the anastomosed intestine was collected including the surrounding adhered tissues; photodocumentation was acquired. The animals were sacrificed after sample collection.

The collected intestine was transected longitudinally on the mesenteric side, pinned onto a cork underlay and the adhesions present on the site of the anastomosis were scored using the perianastomotic adhesions amount score (PAAS) developed previously by our team. PAAS allows for the quantification of the extent of adhesions at the anastomotic circumference (27). The specimens were then fixed in $10 \%$ buffered formalin.

All experimental procedures concerning the pigs were described in a protocol approved by the Commission of Work with Experimental Animals at the Faculty of Medicine in Pilsen, Charles University, and supervised by the Ministry of Education, Youth and Sports of the Czech Republic (project code: MSMT-26570/2017-2). All procedures were performed in compliance with the law of the Czech Republic and with the legislation of the European Union.

Histology. Five $5 \mathrm{~mm}$ thick strips of tissue were cut from each specimen perpendicular to the line of the anastomosis. All specimens were processed by standard paraffin technique. Four $\mu \mathrm{m}$ thick sections were stained by hematoxylin and eosin for comprehensive overview. These samples were investigated both qualitatively and semi-quantitatively. A semiquantitative scoring system has been designed to evaluate the integrity of the intestinal wall at the site of the anastomotic defect. Each layer was assessed separately using defined parameters. Each layer was assigned a 
Table I. Parameters for semiquantitative assessment of anastomotic healing.

\begin{tabular}{lccc}
\hline Layer & Absolute score & Weighted score & Parameter \\
\hline Mucosa & 1 & $3 / 12$ & Completely re-epithelized \\
Submucosa & 0 & $0 / 12$ & Incompletely re-epithelized \\
& 1 & $3 / 12$ & Completely healed \\
Muscularis & 0 & $0 / 12$ & Purulent infiltration, necrosis \\
& 3 & $3 / 12$ & Distance $\leq 0.09 \mathrm{~mm}$ \\
& 2 & $1 / 12$ & Distance $0.1-1.99 \mathrm{~mm}$ \\
Serosa & 1 & $0 / 12$ & Distance $2-3.99 \mathrm{~mm}$ \\
& 0 & $3 / 12$ & Distance $\geq 4 \mathrm{~mm}$ \\
& 2 & $2 / 12$ & Purulent infiltration and/or necrosis from muscular layer to area of nanomaterial* \\
& 1 & $1 / 12$ & Purulent infiltration and/or necrosis from area of nanomaterial to peritoneum* \\
& 0 & $0 / 12$ & Purulent infiltration and/or necrosis passing to peritoneum \\
\hline
\end{tabular}

The absolute score focuses only on the level of integrity of a selected intestinal wall layer, while the weighted score corrects this result to make each layer have the same impact in the total score. *Samples without nanomaterial were scored: score 2 for no necrosis, score $1(2 / 12)$ for purulent infiltration and/or necrosis from muscular layer to $1 / 2$ thickness of serosa and score $0(1 / 12)$ for purulent infiltration and/or necrosis reaching more than $1 / 2$ thickness of serosa to peritoneum.

score ranging from 0 to 0.25 and the scores of all four layers were then summed. The resulting sum (anastomosis integrity score) represents a measure of the deterioration of intestinal wall integrity ranging from 0 (fully defective healing) to 1 (perfect healing) (Table I). A full-thickness defect in the intestinal wall of the specimen was considered a proof of microscopic anastomotic leakage.

The blocks with the highest semiquantitative score were analyzed quantitatively. Five $\mu \mathrm{m}$ sections were stained using picrosirius red (PSR) for the assessment of the amount of collagen. Vascularization and inflammatory infiltration were visualized by immunohistochemical methods. We followed the standardized protocol described in our previous study (27).

Statistical analysis. Common descriptive statistics and frequencies were used to characterize the sample data set. Due to their nonnormal distributions, the PAAS values, anastomosis deficiency scores, and histologically determined volume fractions were analyzed using Kruskal-Wallis ANOVA with respect to group. In case of a significant overall finding, differences between individual group pairs were assessed post-hoc using multiple comparisons of mean ranks according to Siegel and Castellan (28), including a Bonferroni adjustment for multiple testing. All reported $p$-values are two-tailed and the level of statistical significance was set at $\alpha=0.05$. Statistical processing and testing were performed using STATISTICA data analysis software system [Version 12; StatSoft, Inc, 2013; (29)].

\section{Results}

Material properties. Two composite nanofibrous materials were created with mean fibre thicknesses $550 \mathrm{~nm} / 344 \mathrm{~nm}$ for PCL/PVA 1 and $652 \mathrm{~nm} / 344 \mathrm{~nm}$ for PCL/PVA 2 (Figure 2). Both materials were very easy to peel the spunbond underlay and to apply onto the intestinal surface. The level of their adherence to the tissue was sufficient to leave the materials attached without any further fixation.

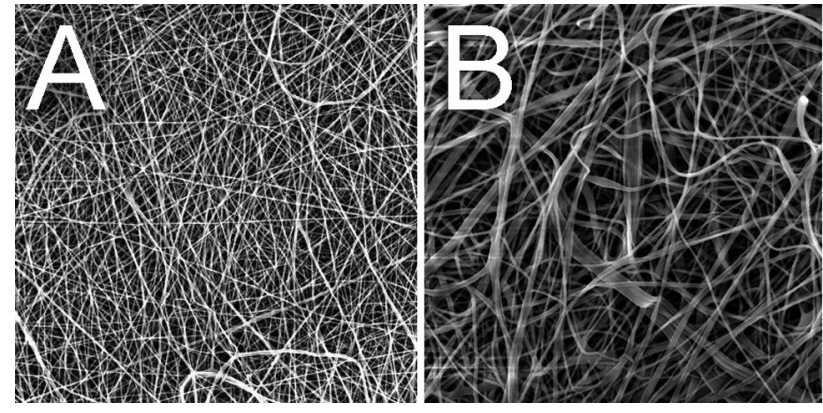

Figure 2. Scanning electron microscopy. Scanning electron microscopy images of the two prepared materials; A) PCL/PVA 1 material; B) PCL/PVA 2 material.

Clinical results. All animals survived through the whole experiment. Re-alimentation was unproblematic in only two animals from the Control group while all of the animals from the PCL/PVA1 and PCL/PVA2 groups were able to feed according to the schedule with no obstacles. Two animals from the Control group vomited once (on $5^{\text {th }}$ POD and $11^{\text {th }}$ POD).

Weight gain was achieved by 3 animals in the PCL/PVA1 group and 6 animals in the PCL/PVA2 group (Table II). Most of the animals did pass stool daily, no animal developed gastrointestinal obstruction. No signs of sepsis or peritonitis were encountered (fevers, activity decrease, abdominal wall tenderness).

Biochemical results. There were no significant deviations from physiological parameters or statistically significant differences between the groups in any of the monitored parameters. 
Table II. Number of animals with weight gain and weight loss per group.

\begin{tabular}{lcc}
\hline Group & $\begin{array}{c}\text { Number of animals having } \\
\text { gained weight (3\% tolerance) }\end{array}$ & $\begin{array}{c}\text { Number of animals having } \\
\text { lost weight (3\% tolerance) }\end{array}$ \\
\hline Control group $(\mathrm{n}=8)$ & 1 & 5 \\
PCL/PVA1 group (n=8) & 3 & 4 \\
PCL/PVA2 group (n=8) & 6 & 1 \\
\hline
\end{tabular}

Table III. Intraoperative macroscopic findings.

\begin{tabular}{lccccc}
\hline Group & $\begin{array}{c}\text { Proximal intestinal } \\
\text { wall thickening } \\
\text { (number of animals) }\end{array}$ & $\begin{array}{c}\text { Partial anastomotic } \\
\text { stenosis } \\
\text { (number of animals) }\end{array}$ & $\begin{array}{c}\text { Mean PAAS } \\
\text { (points) }\end{array}$ & $\begin{array}{c}\text { PAAS range } \\
\text { (points per animal) }\end{array}$ & $\begin{array}{c}\text { Convolute } \\
\text { (number of animals) }\end{array}$ \\
\hline Control group (n=8) & 2 & 0 & 2.63 & $0-5$ & 3 \\
PCL/PVA1 group (n=8) & 6 & 1 & 2.88 & $0-6$ & 5 \\
PCL/PVA2 group (n=8) & 5 & 0 & 4.88 & $3-7$ & 7 \\
\hline
\end{tabular}

PAAS: Perianastomotic adhesions amount score.

Complications. Only minor complications occurred throughout the experiment as there was no animal developing sepsis or signs of complete gastrointestinal obstruction in the whole experiment. There were two cases of infectious complications in the Control group (25\%). One animal developed an abscess in the laparotomy wound without dehiscence and one animal developed infection in the tissues surrounding the central venous catheter. One of the animals in the Control group presented with abdominal diameter enlargement starting on the $17^{\text {th }}$ POD and lasting for 3 days, but with no additional clinical signs, no vomiting, and no defecation problems. One animal from the PCL/PVA1 group (12.5\%) developed an abscess in the laparotomy wound, no other complications were found in the group. One animal from the PCL/PVA2 group (12.5\%) developed a small abscess in the laparotomy wound and another animal from the group showed a mild palpable rash on the abdominal wall from the $14^{\text {th }}$ POD on.

We observed no decrease in activity in any of the animals during the observation period.

Macroscopic findings. All of the anastomoses in both experimental groups and the Control group were free of macroscopically visible defects on the $21^{\text {st }}$ POD. There were no signs of anastomotic leak (no intraperitoneal intestinal matter, no intraperitoneal puss, no abscesses, no visible signs of peritonitis), nor signs of complete intestinal obstruction. However, some level of intestinal wall thickening was visible in the oral parts of the intestine in 2 animals from the Control group (25\%), in 6 from the PCL/PVA1 group (75\%) and in 5 animals from the PCL/PVA2 group (62.5\%). One animal from the PCL/PVA1 group showed a partial stenosis of the anastomosis reducing the intestinal diameter by less than one third (Table III).

Small amount of clear peritoneal fluid was present in almost all animals in volumes smaller than $100 \mathrm{ml}$. The nanomaterial remained fully attached at the place of application until extraction in 5 of $8(62.5 \%)$ animals from the PCL/PVA1 group while it was partially dislocated in the remaining 3 (37.5\%); it always remained covering the place of the defect though. The material was partially dislocated only in 1 of 8 animals (12.5\%) in the PCL/PVA2group, also still covering the place of the defect.

We found a number of adhesions in the area of surgery in all animals except for one animal from the Control group $(12.5 \%)$ and two animals from the CPL/PVA1 group (25\%). The highest perianastomotic adhesions amount score (PAAS) was recorded in the PCL/PVA2 group with a mean PAAS of 4.88 points ( 3 to 7 points per animal), followed by the PCL/PVA1 group with a mean PAAS of 2.88 (0 to 6 points per animal) and by the Control group with a mean PAAS of 2.63 points ( 0 to 5 points per animal). The adhesions were present not only at the location of the anastomosis itself, but usually also in its vicinity, both oral and aboral. An intestinal convolute (more than two segments of intestine adhered together) was present in 3 animals in the Control group $(37.5 \%)$, in 5 animals from the PCL/PVA1 group (62.5\%) and in 7 animals in the PCL/PVA2 group (87.5\%) (Figure 3).

Histology. No signs of full-thickness defects were visible in the comprehensive histologic assessment of the specimens. We observed complete re-epithelialization in the site of the 

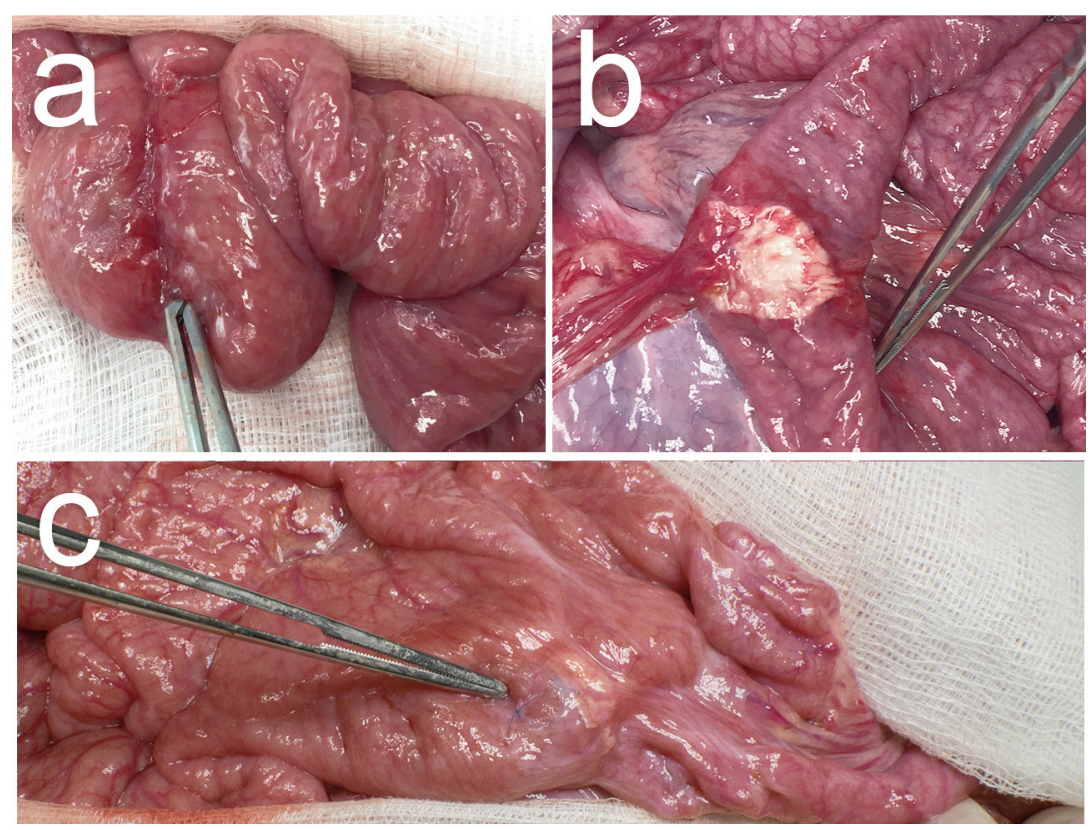

Figure 3. Intraoperative findings. Examples of intraoperative findings, the forceps point to the anastomosis in all of the specimens; A) animal from Control group, well healed anastomosis, no defect is visible; B) animal from PCL/PVA1 group, the material is visible, a string of omental adhesion is attached to the anastomosis, no defect is visible; C) animal from PCL/PVA2 group, multiple adhesions of the anastomosed intestine, material is visible under a layer of peritoneum and peritoneal adhesions.

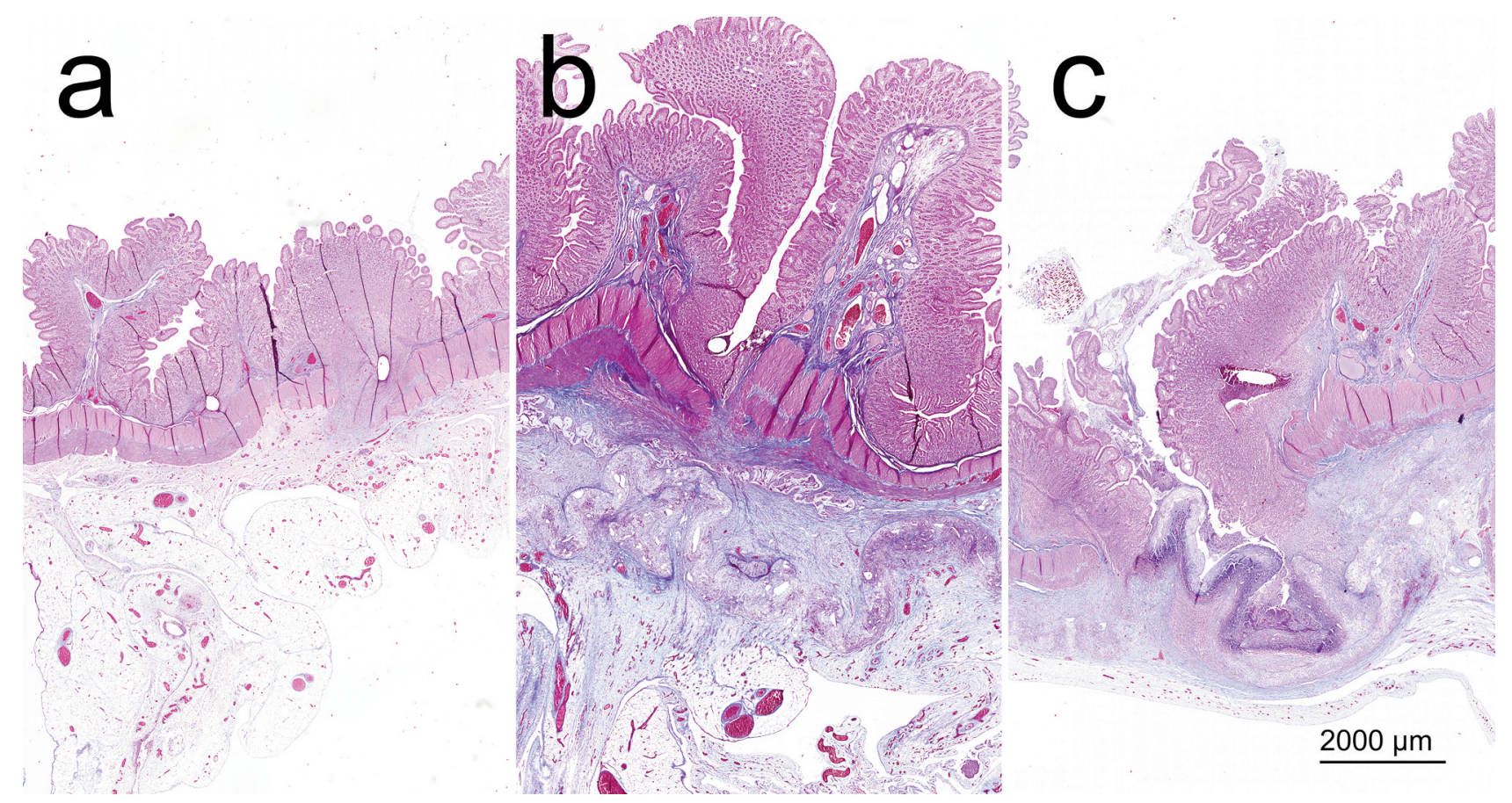

Figure 4. Specimens in blue-trichrome-stained comprehensive histological slides. A) example from the Control group; B) example from the PCL/PVA1 group; $C$ ) example from the PCL/PVA2 group. 
A

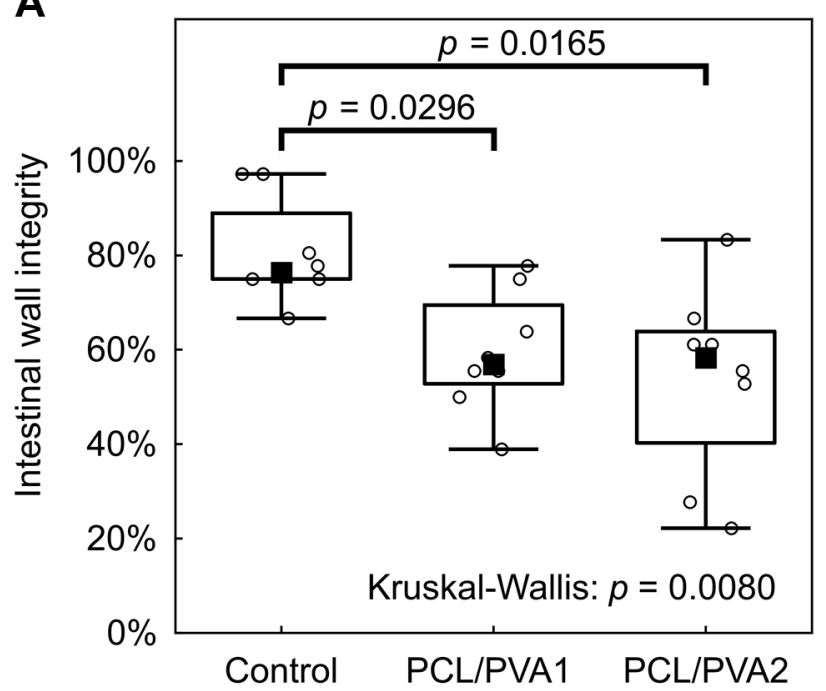

C

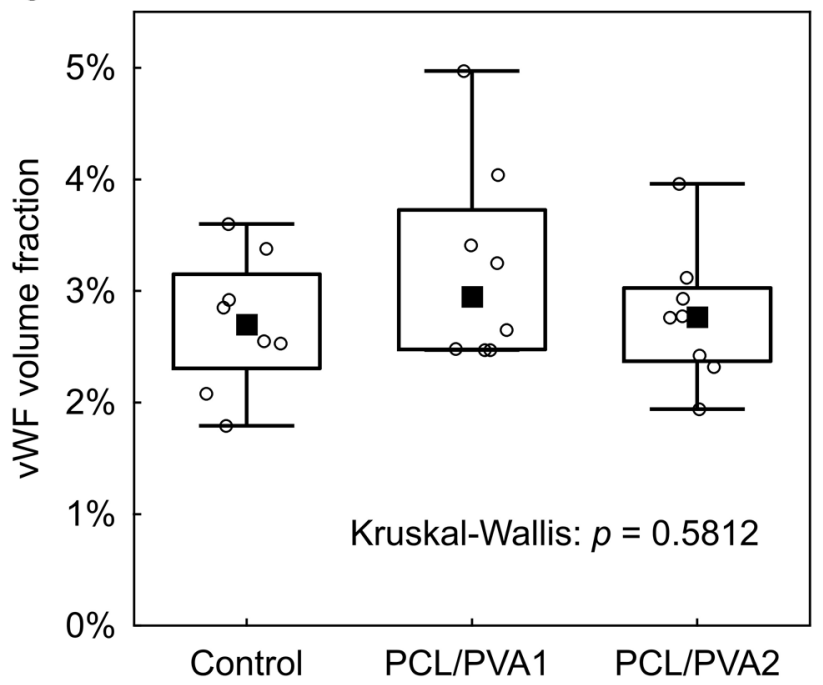

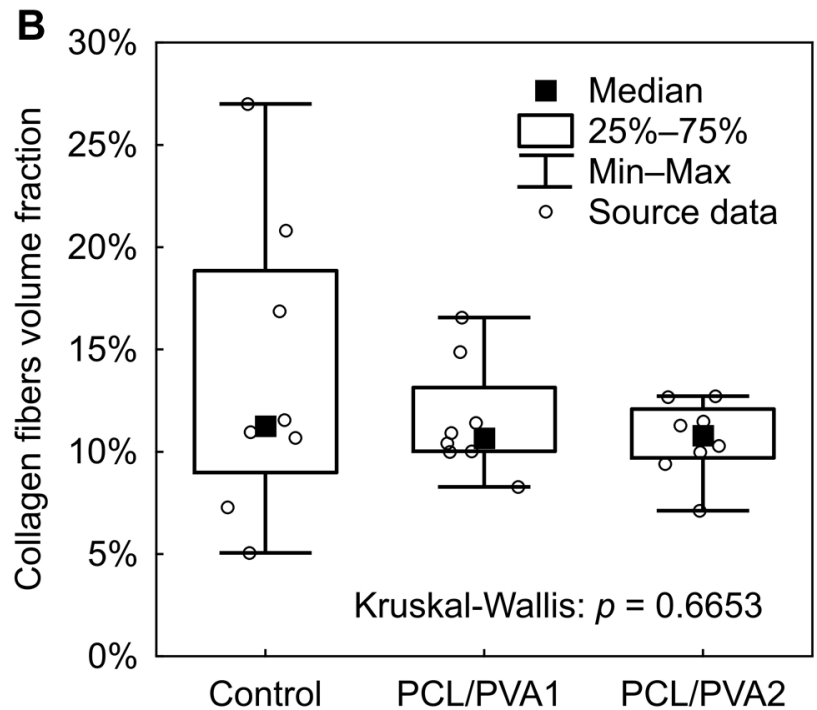

D

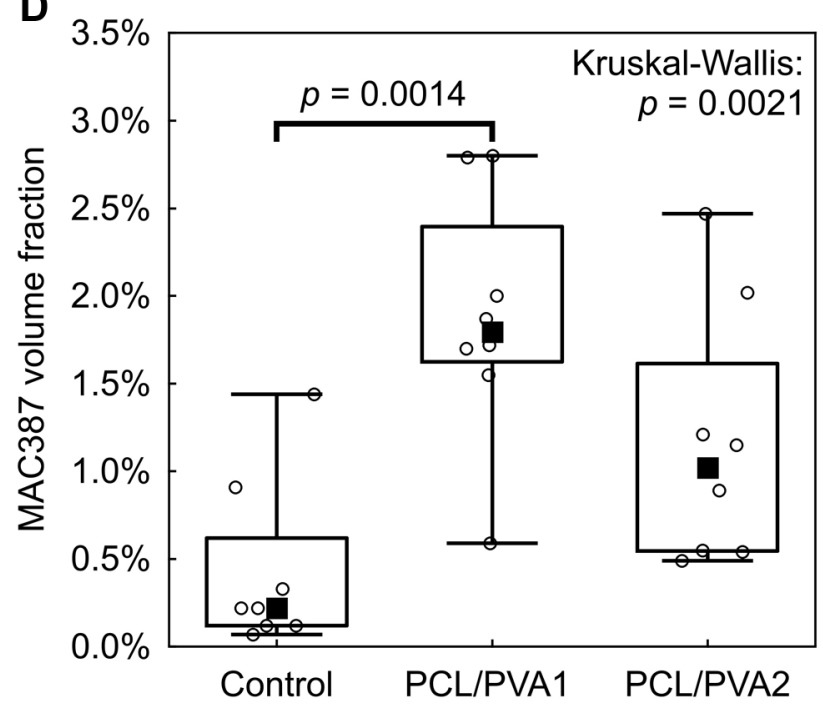

Figure 5. Results of histological evaluation in box plot graphs. A) Anastomosis deficiency score; B) comparison of collagen fibers volume fractions; C) comparison of $v W F$ positive cells volume fractions; D) comparison of MAC387 positive cells volume fractions.

anastomosis in 6 animals from the Control group, yet in no animal from the PCL/PVA1 group and in only one of the animals from the PCL/PVA2 group (Figure 4).

Anastomoses in the experimental groups showed significantly lower intestinal wall integrity according to our histologic evaluation system (Figure 5A).

The volume fraction of inflammatory cells (granulocytes, macrophages) in the tissue surrounding the anastomoses was highest in the PCL/PVA1 group, being significantly higher than in the Control group $(p=0.0097)$ (Figure 5D). The volume fraction of inflammatory cells in the
PCL/PVA2 group did not differ significantly from either the Control group or the PCL/PVA1 group (Figure 5D). Volume fractions of both endothelial cells $(p=0.7063)$ and collagen fibers $(p=0.6094)$ in the area of the anastomoses showed no significant differences between the groups (Figure 5B and C).

The applied nanomaterial was dissolved during the histological staining; however, the place of its application was visible in the histological slides. The two layers of PCL/PVA1 got separated during the follow-up period in all of the specimens (Figure 6). 


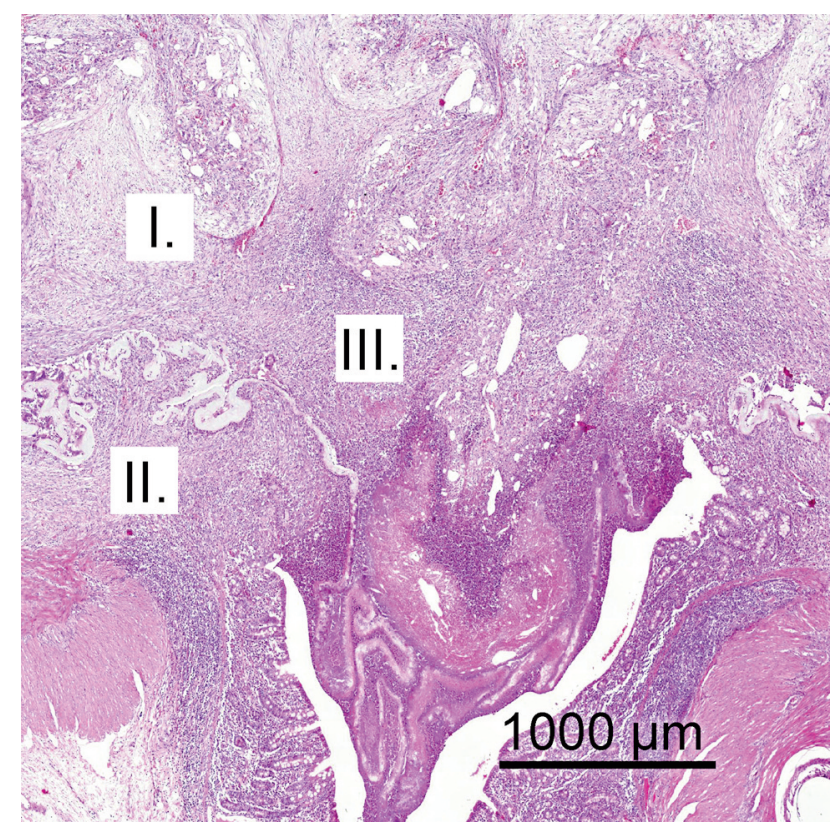

Figure 6. Washed out material imprint. A PCL/PVA1 specimen in blue trichrome staining, the two separated layers of the material are clearly visible.

\section{Discussion}

The experiment successfully and thoroughly investigated basic features of the PCL/PVA1 and PCL/PVA2 microfibrous double-layered materials in relation to healing of a technically defective anastomosis on the small intestine of a pig. We adjusted the model of defective anastomosis designed by Testiti et al. (30), where anastomotic leakage was reached by creating a $2.5 \mathrm{~cm}$ large defect. We, however, created rather smaller defects, which we consider to be more clinically relevant.

Polyvinyl alcohol and polycaprolactone are well-explored polymers known for their biocompatibility and biodegradability. They are routinely used as biodegradable surgical materials with no known adverse effects $(31,32)$. Both presented materials were easy to use and their application did not require any further fixation, which is a valuable aspect not achieved by many other supporting materials $(33,34)$.

There were no major complications and the animals from the experimental groups showed better postoperative weight gain. According to these observations, we conclude that the materials had no adverse effects on the clinical condition of the animals. It is hard to determine to what extent the rash in the one animal from the PCL/PVA2 group was associated with the application of the material $(35,36)$.

It remains unclear whether the materials influence the risk of AL. The material remained at the application site covering the defect in all cases, however, it is questionable whether it could keep the intestinal mass contained underneath and thus prevent the manifestation of AL. A model of defective anastomosis on the large intestine would possibly bring more distinct results (34), however, we intended to test the material first in a model without bacterial contamination for easier assessment of the results. The number of bacteria in the small intestine is minimal compared to the large intestine $(37,38)$.

We consider both materials pro-adhesive according to the obvious macroscopic findings and our scoring system (PAAS). We did not observe any clinical impact of the formed peritoneal adhesions. However, the manifestation of clinical problems due to PAs is not time-limited to the postoperative period, the 3 -week observation is insufficient for definite conclusions. A possible combination with other anti-adhesives is an option worthy of further exploration as the data regarding the safety of their use in gastrointestinal surgery is limited (23). In our study, the material of the outer layer was chosen for its hydrophobicity, which we considered a key factor for adhesion prevention as it has been presumed that the formation of peritoneal adhesions is determined by the level of contact of the two adhering surfaces (39). The materials developed by our team were tested for hydrophobicity prior to this study, and the PVA nanomaterials were shown to be hydrophobic (28), yet the two materials proved pro-adhesive when tested in our experiment.

We created and used a new system for the evaluation of intestinal wall integrity at the site of anastomosis on the gastrointestinal tract. It evaluates the integrity of each layer separately, thus making the evaluation of anastomotic healing more precise. In combination with stereological quantitative techniques such as PAAS and Zühlke's grading, it forms probably the most complex evaluation system for anastomotic healing compared to the literature (40-43).

According to our intestinal wall integrity evaluation, the histological assessment suggests inferior healing quality when the material is applied. The PCL/PVA1 group showed higher inflammatory reaction, yet other parameters did not differ significantly from the Control group. The higher inflammatory infiltration could, however, suggest an ongoing healing process. Inflammation is a driving mechanism for cellular proliferation of peritoneal fibroblasts, smooth muscle cells and also intestinal epithelium (44-46). Results of the PCL/PVA2 group were not statistically different from those of the Control group in any of the three monitored aspects. No abnormal vascularization, no abnormal collagen production or inflammation were observed as a reaction to the presence of the material, which is considered normal anastomotic healing (18). Even though the integrity of the intestinal wall was significantly lower in the experimental groups, connective tissue surrounding the material residues was visible in all of the specimens, covering the place of defect. It is possible that in this way the material kept the luminal contents from leaking into the peritoneal cavity. 
It is not possible in our settings to distinguish the direction of the healing process. Complete healing ad integrum or manifestation of $\mathrm{AL}$ seem both real possibilities for future development in the experimental groups. The same holds for possible occurrence of anastomotic strictures. Sounder results could be acquired in a longer observation period (47, 48). This is a certain limitation of the study.

We decided not to perform mechanical tests to investigate bursting pressure or similar parameters as there is no evidence for the relation between the results of these and the risk of AL (49). Such tests can also compromise the quality of the samples for later histologic evaluation. Biodegradability tests were not employed in our study as this parameter was already studied for PCL and PVA $(50,51)$.

Both materials exhibited mixed results in the study. The healing quality seems to be compromised when compared to the previous study with polycaprolactone nanofibrous material (27). It is a question whether the change of the characteristics of the material or the change of experimental settings (or possibly a combination of both) can be blamed. The materials need to be studied further after specific adjustments of their properties in new experimental settings in order to fully determine their clinical potential, probably with even more hydrophobic materials.

\section{Conclusion}

We were the first to propose a double layered nanomaterial for prevention of both anastomotic leakage and peritoneal adhesions. Both materials tested in our study did not have negative effects on clinical results in the postoperative period. No major complications appeared. Macroscopic findings suggest that both materials are pro-adhesive. Histological assessments of the specimens confirmed no microscopic signs of anastomotic leakage. The specimens from the control group were more completely healed according to our intestinal wall integrity score. However, the material always remained covering the defect and no anastomotic leakage developed. We intend to further investigate the possibility of using nano- and microfibrous materials to determine their clinical impact.

\section{Conflicts of Interest}

The Authors certify that they have no affiliations with or involvement in any organization or entity with any financial interest, or non-financial interest in the subject matter or materials discussed in this manuscript.

\section{Authors' Contributions}

Conceptualization: J. R., V. L., M. K.; methodology: J. R., J. H., P. H., O. B., Z. T., A. K., L. B., V. T., R. P.; supervision: V. L., V. T., D. L., writing original draft: J. R., M. K., original draft review and editing: V. M., formal analysis: P. H.

\section{Acknowledgements}

The research was funded by the project Czech health research council project AZV NU20J-08-00009 Prevention of intestinal anastomotic leakage and postoperative adhesions by using nanofibrous biodegradable materials, and by Charles University Grant Agency project number 1612319: Double-layer nanomaterials as a solution for gastrointestinal anastomoses leakage in a piglet experimental model.

\section{References}

1 Qu H, Liu Y and Bi DS: Clinical risk factors for anastomotic leakage after laparoscopic anterior resection for rectal cancer: a systematic review and meta-analysis. Surg Endosc 29(12): 36083617, 2015. PMID: 25743996. DOI: 10.1007/s00464-015-4117-x

2 Meyer J, Naiken S, Christou N, Liot E, Toso CH, Buchs NCH and Ris F: Reducing anastomotic leak in colorectal surgery: The old dogmas and the new challenges. World J Gastroenterol 25(34): 5017-5025, 2019. PMID: 25743996. DOI: 10.3748/wjg.v25. i34.5017

3 Sciuto A, Merola G, De Palma GD, Sodo M, Pirozzi F, Bracale UM and Bracale U: Predictive factors for anastomotic leakage after laparoscopic colorectal surgery. World J Gastroenterol 24(21): 2247-2260, 2018. PMID: 29881234. DOI: 10.3748/wjg. v24.i21.2247

4 Bouassida M, Charrada H, Chtourou MF, Hamzaoui L, Mighri MM, Sassi S, Azzouz MM and Touinsi H: Surgery for colorectal cancer in elderly patients: How could we improve early outcomes? J Clin Diagn Res 9(5): PC04-8, 2015. PMID: 26155516. DOI: 10.7860/JCDR/2015/12213.5973

5 Paun BC, Cassie S, MacLean AR, Dixon E and Buie WD: Postoperative complications following surgery for rectal cancer. Ann Surg 251: 807-818, 2010. PMID: 20395841. DOI: 10.1097/ SLA.0b013e3181dae4ed

62015 European Society of Coloproctology collaborating group: The relationship between method of anastomosis and anastomotic failure after right hemicolectomy and ileo-caecal resection: An international snapshot audit. Colorectal Dis 19(8): e296-e311, 2017. PMID: 28263043. DOI: 10.1111/codi.13646

7 Krarup PM, Jorgensen LN, Andreasen AH, Harling H and Danish Colorectal Cancer Group: A nationwide study on anastomotic leakage after colonic cancer surgery. Colorectal Dis 14: e661-e667, 2012. PMID: 22564292. DOI: 10.1111/j.1463-1318.2012.03079.x

8 Yun JA, Cho YB, Park YA, Huh JW, Yun SH, Kim HC and Lee WY: Clinical manifestations and risk factors of anastomotic leakage after low anterior resection for rectal cancer. ANZ J Surg 87(11): 908-914, 2017. PMID: 25925005. DOI: 10.1111/ans.13143

9 Platell C, Barwood N, Dorfmann G and Makin G: The incidence of anastomotic leaks in patients undergoing colorectal surgery. Colorectal Dis 9(1): 71, 2007. PMID: 17181849. DOI: 10.1111/ j.1463-1318.2006.01002.x

10 Kingham TP and Pachter HL: Colonic anastomotic leak: risk factors, diagnosis, and treatment. J Am Coll Surg 208(2): 269, 2009. PMID: 19228539. DOI: 10.1016/j.jamcollsurg.2008.10.015

11 Bruce J, Krukowski ZH, Al-Khairy G, Russell EM and Park KG: Systematic review of the definition and measurement of anastomotic leak after gastrointestinal surgery. Br J Surg 88: 1157-1168, 2001. PMID: 11531861. DOI: 10.1046/j.0007-1323.2001.01829.x 
12 Rahbari NN, Weitz J, Hohenberger W, Heald RJ, Moran B, Ulrich A, Holm T, Wong WD, Tiret E, Moriya Y, Laurberg S, den Dulk M, van de Velde C and Büchler MW: Definition and grading of anastomotic leakage following anterior resection of the rectum: a proposal by the International Study Group of Rectal Cancer. Surgery 147(3): 339-351, 2010. PMID: 20004450. DOI: 10.1016/j.surg.2009.10.012

13 Vallance A, Wexner S, Berho M, Cahill R, Coleman M, Haboubi N, Heald RJ, Kennedy RH, Moran B, Mortensen N, Motson RW, Novell R, O'Connell PR, Ris F, Rockall T, Senapati A, Windsor A and Jayne DG: A collaborative review of the current concepts and challenges of anastomotic leaks in colorectal surgery. Colorectal Dis 19: O1-O12, 2017. PMID: 27671222. DOI: 10.1111/codi.13534

14 Ashraf SQ, Burns EM, Jani A, Altman S, Young JD, Cunningham $\mathrm{C}$, Faiz $\mathrm{O}$ and Mortensen NJ: The economic impact of anastomotic leakage after anterior resections in English NHS hospitals: Are we adequately remunerating them? Colorectal Dis 15: e190-e198, 2013. PMID: 23331871. DOI: $10.1111 /$ codi.12125

15 Wang S, Liu J, Wang S, Zhao H, Ge S and Wang W: Adverse effects of anastomotic leakage on local recurrence and survival after curative anterior resection for rectal Cancer: A systematic review and meta-analysis. World J Surg 41: 277-284, 2017. PMID: 27743072. DOI: 10.1007/s00268-016-3761-1

$16 \mathrm{Ha} \mathrm{GW,} \mathrm{Kim} \mathrm{JH} \mathrm{and} \mathrm{Lee} \mathrm{MR:} \mathrm{Oncologic} \mathrm{impact} \mathrm{of} \mathrm{anastomotic}$ leakage following colorectal cancer surgery: a systematic review and meta-analysis. Ann Surg Oncol 24: 3289-3299, 2017. PMID: 28608118. DOI: $10.1245 / \mathrm{s} 10434-017-5881-8$

17 Smith JD, Paty PB, Guillem JG, Temple LK, Weiser MR and Nash GM: Anastomotic leak is not associated with oncologic outcome in patients undergoing low anterior resection for rectal cancer. Ann Surg 256: 1034-1038, 2012. PMID: 22584695. DOI: 10.1097/ SLA.0b013e318257d2c1

18 Williams DL and Browder IW: Murine models of intestinal anastomoses. In: Wound healing: Methods and protocols, 1st edition. DiPietro LA, Burns AL (eds.), New Jersey: Humana Press Inc. pp. 133-140, 2010.

19 Marinello FG, Baguena G, Lucas E, Frasson M, Hervás D, FlorLorente B, Esclapez P, Espí A and García-Granero E: Anastomotic leakage after colon cancer resection: does the individual surgeon matter? Colorectal Dis 18: 562-569, 2016. PMID: 26558741. DOI: 10.1111/codi.13212

20 García-Granero E, Navarro F, Cerdán Santacruz C, Frasson M, García-Granero A, Marinello F, Flor-Lorente B and Espí A: Individual surgeon is an independent risk factor for leak after double-stapled colorectal anastomosis: An institutional analysis of 800 patients. Surgery 162: 1006-1016, 2017. PMID: 28739093. DOI: 10.1016/j.surg.2017.05.023

21 Nikolian VC, Kamdar NS, Regenbogen SE, Morris AM, Byrn JC, Suwanabol PA and Campbell DA Jr: Anastomotic leak after colorectal resection: A population-based study of risk factors and hospital variation. Surgery 161: 1619-1627, 2017. PMID: 28238345. DOI: $10.1016 /$ j.surg.2016.12.033

22 van Goor H: Consequences and complications of peritoneal adhesions. Colorectal Dis 9: 25-34, 2007. PMID: 17824967. DOI: 10.1111/j.1463-1318.2007.01358.x

23 Ouaïssi M, Gaujoux S, Veyrie N, Denève E, Brigand C, Castel B, Duron JJ, Rault A, Slim K and Nocca D: Post-operative adhesions after digestive surgery: their incidence and prevention: review of the literature. J Visc Surg 149(2): e104-14, 2012. PMID: 22261580. DOI: 10.1016/j.jviscsurg.2011.11.006
24 Yauw ST, Wever KE, Hoesseini A, Ritskes-Hoitinga M and van Goor H: Systematic review of experimental studies on intestinal anastomosis. Br J Surg 102(7): 726-734, 2015. PMID: 25846745. DOI: $10.1002 /$ bjs .9776

25 Hunt SL and Silviera ML: Anastomotic construction. In: The ASCRS Textbook of Colon and Rectal Surgery, $3^{\text {rd }}$ edition. Steele SR, Hull TL, Hyman N, Maykel JA, Read ThE, Whitlow CB (eds.), New York: Springer, pp. 141-160, 2016.

26 Gholipour-Kanani A, Bahrami SH, Joghataie MT, Samadikuchaksaraei A, Ahmadi-Taftie H, Rabbani S, Kororian A and Erfani E: Tissue engineered poly(caprolactone)-chitosanpoly(vinyl alcohol) nanofibrous scaffolds for burn and cutting wound healing. IET Nanobiotechnol 8(2): 123-131, 2014. PMID: 25014084. DOI: 10.1049/iet-nbt.2012.0050

27 Rosendorf J., Horakov J., Klicova M., Palek R., Cervenkova L, Kural T, Hosek P, Kriz T, Tegl V, Moulisova V, Tonar Z, Treska V, Lukas D and Liska V: Experimental fortification of intestinal anastomoses with nanofibrous materials in a large animal model. Sci Rep 10: 1134, 2020. PMID: 31980716. DOI: 10.1038/s41598020-58113-4

28 Siegel S and Castellan Jr. NJ: Nonparametric Statistics for the Behavioral Sciences. McGraw-Hill, New York. pp. 213-215, 1988. DOI: $10.1177 / 014662168901300212$

29 StatSoft Europe. Available at: https://www.statsoft.de/en/home [Last accessed on January 21 2021]

30 Testini M, Gurrado A, Portincasa P, Scacco S, Marzullo A, Piccinni G, Lissidini G, Greco L, De Salvia MA, Bonfrate L, Debellis L, Sardaro N, Staffieri F, Carratù MR and Crovace A: Bovine pericardium patch wrapping intestinal anastomosis improves healing process and prevents leakage in a pig model. PLoS One 9(1): e86627, 2014. PMID: 24489752. DOI: 10.1371/journal.pone. 0086627

31 Baker MI, Walsh SP, Schwartz Z and Boyan BD: A review of polyvinyl alcohol and its uses in cartilage and orthopedic applications. J Biomed Mater Res B Appl Biomater 100(5): 14511457, 2012. PMID: 22514196. DOI: 10.1002/jbm.b.32694

32 Cai EZ, Teo EY, Jing L, Koh YP, Qian TS, Wen F, Lee JW, Hing EC, Yap YL, Lee H, Lee CN, Teoh SH, Lim J and Lim TC: Bioconjugated polycaprolactone membranes: a novel wound dressing. Arch Plast Surg 41(6): 638-646, 2014. DOI: 10.5999/aps.2014. 41.6.638

33 Kwon TR, Han SW, Yeo IK, Kim JH, Kim JM, Hong JY, Lee BC, Lee SE, Moon HS, Kwon HJ and Kim BJ: Biostimulatory effects of polydioxanone, poly-d, 1 lactic acid, and polycaprolactone fillers in mouse model. J Cosmet Dermatol 18(4): 1002-1008, 2019. PMID: 30985064. DOI: 10.1111/jocd.12950

34 García-Vásquez C, Fernández-Aceñero MJ, García Gómez-Heras $\mathrm{S}$ and Pastor C: Fibrin patch influences the expression of hypoxiainducible factor- $1 \alpha$ and nuclear factor-kBp65 factors on ischemic intestinal anastomosis. Exp Biol Med (Maywood) 243(10): 803808, 2018. PMID: 29932372. DOI: 10.1177/1535370218777216

35 McLoughlin CE, Smith MJ, Auttachoat W, Bowlin GL and White KL Jr: Evaluation of innate, humoral and cell-mediated immunity in mice following in vivo implantation of electrospun polycaprolactone. Biomed Mater 7(3): 035015, 2017. PMID: 22539041. DOI: $10.1088 / 1748-6041 / 7 / 3 / 035015$

36 Yao NZ, Huang C and Jin DD: Evaluation of biocompatibility of a pectin/polyvinyl alcohol composite hydrogel as a new nucleus material. Orthop Surg 1(3): 231-237, 2009. PMID: 22009848. DOI: $10.1111 / \mathrm{j} .1757-7861.2009 .00036 . x$ 
37 Mancabelli L, Milani C, Lugli GA, Turroni F, Ferrario C, van Sinderen D and Ventura M: Meta-analysis of the human gut microbiome from urbanized and pre-agricultural populations. Environ Microbiol 19(4): 1379-1390, 2017. PMID: 28198087. DOI: $10.1111 / 1462-2920.13692$

38 Duvallet C, Gibbons SM, Gurry T, Irizarry RA and Alm EJ: Metaanalysis of gut microbiome studies identifies disease-specific and shared responses. Nat Commun 8(1): 1784, 2017. PMID: 29209090. DOI: 10.1038/s41467-017-01973-8

39 Chen Y and Hills BA: Surgical adhesions: evidence for adsorption of surfactant to peritoneal mesothelium. Aust N Z J Surg 70(6): 443-447, 2000. PMID: 10843402. DOI: 10.1046/j.1440-1622. 2000.01841.x

40 Fletcher NM, Awonuga AO, Abusamaan MS, Saed MG, Diamond MP and Saed GM: Adhesion phenotype manifests an altered metabolic profile favoring glycolysis. Fertil Steril 105(6): 16281637.e1, 2016. PMID: 26947752. DOI: 10.1016/j.fertnstert. 2016.02.009

41 Fortin CN, Saed GM and Diamond MP: Predisposing factors to post-operative adhesion development. Hum Reprod Update 21(4): 536-551, 2015. PMID: 25935859. DOI: 10.1093/humupd/ dmv021

42 Lovisa S, Genovese G and Danese S: Role of Epithelial-toMesenchymal Transition in Inflammatory Bowel Disease. J Crohns Colitis 13(5): 659-668, 2019. PMID: 30520951. DOI: 10.1093/ ecco-jcc/jjy201

43 Boersema GSA, Vennix S, Wu Z, Te Lintel Hekkert M, Duncker DGM, Lam KH, Menon AG, Kleinrensink GJ and Lange JF: Reinforcement of the colon anastomosis with cyanoacrylate glue: a porcine model. J Surg Res 217: 84-91, 2017. PMID: 28595813. DOI: $10.1016 /$ j.jss.2017.05.001

44 Naito M, Sato T, Nakamura T, Yamanashi T, Miura H, Tsutsui A, Yamashita $\mathrm{K}$ and Watanabe M: Secure overlap stapling using a linear stapler with bioabsorbable polyglycolic acid felt. Asian J Endosc Surg 10(3): 308-312, 2017. PMID: 28224709. DOI: 10.1111/ases. 12364
45 Ikeda T, Kumashiro R, Oki E, Taketani K, Ando K, Aishima S, Akahoshi T and Morita M, Maehara Y: Evaluation of techniques to prevent colorectal anastomotic leakage. World J Gastrointest Surg 7(12): 378-383, 2015. PMID: 26730283. DOI: 10.4240/wjgs. v7.i12.378

46 Nordentoft T: Sealing of gastrointestinal anastomoses with fibrin glue coated collagen patch. Dan Med J 62(5): B5081, 2015. PMID: 26050838.

47 Hyman N, Manchester TL, Osler T, Burns B and Cataldo PA: Anastomotic leaks after intestinal anastomosis: it's later than you think. Ann Surg 245(2): 254, 2007. PMID: 17245179. DOI: 10.1097/01.sla.0000225083.27182.85

48 Strik C, Stommel MW, Schipper LJ, van Goor H and Ten Broek RP: Long-term impact of adhesions on bowel obstruction. Surgery 159(5): 1351-1359, 2016. PMID: 26767310. DOI: 10.1016/j.surg. 2015.11.016

49 Vakalopoulos KA, Wu Z, Kroese L, Kleinrensink GJ, Jeekel J, Vendamme R, Dodou D and Lange JF: Mechanical strength and rheological properties of tissue adhesives with regard to colorectal anastomosis: an ex vivo study. Ann Surg 261(2): 323-331, 2015. PMID: 24670843. DOI: 10.1097/SLA.0000000000000599

50 Horakova J, Mikes P, Saman A, Jencova V, Klapstova A, Svarcova T, Ackermann M, Novotny V, Suchy T and Lukas D: The effect of ethylene oxide sterilization on electrospun vascular grafts made from biodegradable polyesters. Mater Sci Eng C Mater Biol Appl 92: 132-142, 2018. PMID: 30184736. DOI: 10.1016/j.msec. 2018.06.041

51 Klicova M, Klapstova A, Chvojka J, Koprivova B, Jencova V and Horakova J. Novel double-layered planar scaffold combining electrospun PCL fibers and PVA hydrogels with high shape integrity and water stability. Mater Lett 263, 2020. DOI: 10.1016/j.matlet.2019.127281

Received December 24, 2020

Revised January 17, 2021

Accepted January 21, 2021 